\title{
Epidemiology, Incidence, and Mortality of Leukemia in Children Early Infancy to 14 Years Old of Age in South-Central Asia: A Global Ecological Study
}

\author{
Zaher Khazaei ${ }^{1}$, Elham Goodarzi ${ }^{2,{ }^{*}, \text {, Hossein Ali Adineh }}{ }^{3}$, Yousef Moradi ${ }^{4}$, Malihe Sohrabivafa ${ }^{5}$, Isan \\ Darvishi ${ }^{6}$ and Seyedeh Leila Dehghani ${ }^{7}$ \\ ${ }^{1}$ Student Research Committee, Sabzevar University of Medical Sciences, Sabzevar, Iran \\ ${ }^{2}$ Social Determinants of Health Research Center, Lorestan University of Medical Sciences, Khorramabad, Iran \\ ${ }^{3}$ Department of Epidemiology and Biostatistics, Iranshahr University of Medical Sciences, Iranshahr, Iran \\ ${ }^{4}$ Pars Advanced and Minimally Invasive Medical Manners Research Center, Pars Hospital, Iran University of Medical Science, Tehran, Iran \\ ${ }^{5}$ Department of Health and Community Medicine, Faculty of Medicine, Dezful University of Medical Sciences, Dezful, Iran \\ ${ }^{6}$ Surgical Technology Department, School of Nursing and Midwifery, Shiraz University of Medical Sciences and Healthcare Services. Shiraz, Iran \\ ${ }^{7}$ Behbahan Faculty of Medical Sciences, Behbahan, Iran \\ "Corresponding author: Social Determinants of Health Research Center, Lorestan University of Medical Sciences, Khorramabad, Iran. Email: elhamgoodarzi.1370@yahoo.com
}

Received 2018 July 16; Revised 2018 September 03; Accepted 2018 October 07.

\begin{abstract}
Background: The cancer was considered the second cause of death from early infancy to 14 years of age after the inadvertent damage. Also, leukemia was reported as the most common type of cancer in infants.

objectives: The current study was aimed to evaluate the epidemiology, incidence, and mortality rates of leukemia from early infancy to 14 years of age in South-Central Asia.

Methods: This is a descriptive cross-sectional study. In the current study, the incidence and mortality rates of leukemia in South-Central Asia were determined. The data were extracted from a Cancer Global Project in 2012 available at http://globocan.iarc.fr/Default.aspx.

Results: In South-Central Asia, 1514027 cases of cancer were recorded in 2012 in which 480267 cases (3.2\%) were related to leukemia. The highest incidence rates of leukemia were reported for Iran, Kazakhstan, Sri Lanka, and Uzbekistan with the ratio of 3.6, 3.2, and 3 cases per 100000 people, respectively compared with the lowest incidence rates in Bangladesh, and Bhutan with the ratio of 0.8 and 0.9 cases per 100000 people, respectively in under14-year-old infants.

Conclusions: Leukemia was reported as the most common type of cancer in infants, providing important information about possible changes of risk factors considering that its trend might help us to find critical ways so as to decrease the rate of cancer in infants.
\end{abstract}

Keywords: Incidence, Mortality, Leukemia, Infants, South-Central Asia

\section{Background}

The cancer is considered the second cause of death around the world, especially in the developed countries after cardiovascular diseases $(1,2)$ and the third cause of death in less-developed countries after cardiovascular diseases and accidents (2). The rate of cancer was estimated at $<1 \%$ of the total cancers from early infancy to 14 -year-old age group $(6,7)$.

The cancer was reported as one of the main causes of death among the infants $(8,9)$. It was considered the second cause of death from early infancy to 14 years of the age after the inadvertent damages with the mortality rate of
0.41 deaths per 10000 infants (10).

The most common types of cancer, based on the rate of incidence in infants, were reported as acute lymphoblastic leukemia, central nervous system tumors, and lymphoma, respectively constituting half of the total malignancies in infants $(7,11)$. Leukemia was defined as the malignant switch of hematopoietic precursor cells categorized into lymphoid and myeloid lineages based on the type of the cell, and acute or chronic condition of the disease $(11,12)$. The etiology of infantile leukemia still remained to be determined. The epidemiologic studies assessed the risk factors for leukemia, including environmental, genetic, and infectious factors $(13,14)$. 
Leukemia in children can be generated by genetic factors such as Down syndrome, Fanconi anemia, Bloom syndrome, and Custman syndrome. Exposure to some medications such as alcohol and urea nitrogen and ionizing radiation can also cause this disorder (15).

Thirty-two percent of infantile cancers are related to leukemia (16). Furthermore, leukemia was indicated as the most common type of malignancy in under 15-year-old infants with the ratio of 40/1000000 people suggesting some $30 \%$ of the overall cancers in infants $(17,18)$.

The acute leukemia was demonstrated in $80 \%$ of the infants suffering from leukemia in the developed countries with the incidence ratio of 34.3:1000000 people (19). The incidence ratio of leukemia was ranged from 4 to 9 cases per 1 million people in Europe. In addition, 20\% to 25\% of all leukemia cancers diagnosed in under 15-year-old infants accounted for ALM and CML with the rate of 300 to 350 cases in European Union countries annually. Also, the incidence ratio of leukemia was ranged from 7.1 to 8.9 cases per 1 million infants $(20,21)$. The lowest incidence rates of leukemia were reported in Middle and Western Africa (being $<$ 3:100000 in males and $<2: 100000$ in females) compared with the highest incidence rates in Northern America and Australia ( $>$ 10:100000 in males and > 7:100000 in females) (3).

The incidence rate of acute leukemia was estimated at less than $3 \%$ of the total cancers significantly remarked owing to a high rate of mortality (8). The mortality ratio for males and females were ranged from 1.3 to 6.3 and 1.1 to 3.8 per 100000 people, respectively. The low incidence and mortality rates resulted from the lack of disease diagnosis in South-Saharan Africa (3).

The treatment of these patients is done by two approaches. In the first approach, chemotherapy is used and in the second approach, after the initial chemotherapy, a stem cell transplant is used (15).

The data related to the incidence and mortality rates in different populations might provide important information about risk factors and possible changes.

\section{Objectives}

Thus the current study was aimed to evaluate the epidemiology, incidence, and mortality rates of leukemia from early infancy to 14-year-old infants in South-Central Asia.

\section{Methods}

This is a descriptive cross-sectional study. In the current study, the incidence and mortality rates of leukemia in South-Central Asia were determined. The data were extracted from a Cancer Global Project in 2012 available at http://globocan.iarc.fr/Default.aspx.

\subsection{Age-Specific Incidence Rates}

The methods of estimation are country-specific and the quality of the estimation depends upon the quality and on the amount of the information available for each country. In theory, there are as many methods as countries and because of the variety and the complexity of these methods, an overall quality score is almost impossible to establish for the incidence and mortality estimation. However, an alphanumeric scoring system which independently describes the availability of the incidence and mortality data was established at the country level. The combined score is presented together with the estimates for each country to provide a broad indication of the robustness of the estimation. The methods to estimate the gender- and age-specific incidence rates of cancer for a specific country fall into one of the following broad categories according to priority order: (1) rates of the projects until 2012 (38 countries), (2) most recent rates applied to 2012 population (20 countries), (3) estimated at national mortality by modeling, using incidence mortality ratios derived from recorded data in country-specific cancer registries (13 countries), (4) estimated at national mortality estimates by modeling, using incidence mortality ratios derived from recorded data in local cancer registries in neighboring countries (9 European countries), (5) estimated at national mortality estimates using modeled survival (32 countries), (6) estimated at the calculated average of the local rates (16 countries), (7) one cancer registry covering part of a country was used as representative of the country profile (11 countries), (8) age/gender-specific rates for "all cancers" were partitioned using data on the relative frequency of different cancers (by age and gender) (12 countries), and (9) the rates of neighboring countries or registries in the same area (33 countries).

\subsection{Age-Specific Mortality Rate}

Depending on the degree of detail and accuracy of the national mortality data, six methods were utilized in the following order of priority: (1) rates of the projects until 2012 (69 countries), (2) most recent rates applied to 2012 population (26 countries), (3) estimated at the calculated 
average of regional rates ( 1 country), (4) estimated at national incidence estimates by modeling, using countryspecific survival (2 countries), (5) estimated at national incidence estimates using modeled survival (83 countries), and (6) the rates of neighboring countries or registries in the same area (3 countries) (3).

\section{Results}

In 2012, South-Central Asia has reported 151407 cases of cancer, of which 48067 (3.2\%) are related to leukemia (Figure 1). Of these, 28870 (1/4\%) were in men and 28498 (6.3\%) in women. India (32532 cases), Pakistan (4609 cases), and Iran (3926 cases) had the highest reported incidence rates. Iran (5.8 out of 100000) and Pakistan (5.7 out of 100000) had the highest incidence, which the highest incidence in women related to Kazakhstan and in men related to Iran. In South-Central Asia in 2012, 102440 deaths were reported due to total cancers, of which 4470 (3.9\%) died due to leukemia. India (26712 cases), Pakistan (4180 cases), and Iran (3064 cases) had the highest death rates for leukemia, with the highest death rates for women (3.8 per 100000) and the highest death rates for men (4.5 out of 100000) in Iran (Table 1 and Figure 1).

In the study of incidence rates in the age group under 14 years of age, in both sexes, Iran and Kazakhstan had the highest incidence of leukemia in the age group of 0 - 14 years, with the incidence rate of 3.6 in 100000, the highest incidence in girls was observed in Kazakhstan (3.4 in 1000000 people) and the boys in the Maldives (4.4 in 100000 ) (Table 2 and Figure 2). In the study of mortality rate in the age group under 14 years, Maldives (2.5 in 100000 ) and Nepal (3.2 in 100000) had the highest mortality rates, with the highest death rates in girls from Iran and Kazakhstan (8/1 in 1000000 people) and in boys in the Maldives (4.4 in 100000) (Table 2, Figure 2 and 3).

\section{Discussion}

Prominent progress was obtained in treating infantile cancers during the last decades, however, leukemia was reported as one of the most important factors in infantile mortality (22). Massive therapeutic costs, hospitalization length, and psychological problems indicated the heavy burden of the socio-economic situation of leukemia. Approximately, 10.4 million dollars are paid so as to treat acute leukemia in infants in the United States annually (23).
The highest ratio of incidence in under 14-year-old infants in South-Central Asia was reported in Iran, Kazakhstan, Sri Lanka, and Uzbekistan with 3.6, 3.6, 3.2, and 3 cases per 100000 people, respectively. Moreover, the highest ratio of mortality under 14-year-old infants in SouthCentral Asia was reported in Maldives, Nepal, and Uzbekistan with 2.5, 2.3, and 2.2 cases per 100000 people, respectively.

Only $10 \%$ of the cases of childhood cancers have been clinically and epidemiologically distinguished and no specific etiology has been identified in $90 \%$ of the cases. It seems that childhood leukemia, as well as other cancers, are multifactorial disorders in which environmental and genetic factors play important roles (13).

About 59014 new cases of leukemia with a mortality rate of 37010 were estimated in 2013, which might significantly develop in Northern America and New Zealand compared with the insignificant development in Europe toward Asia region and less-developed countries.

The different rates of mortality of leukemia in the developed countries rather than other countries could be due to different healthcare systems, production and accessibility of effective medications, and stem cell implantation for some types of leukemia (24).

The estimates of incidence related to leukemia from early infancy to 14 years of age in Eastern Asia, including China and Japan, were 2.6, and 3.3 cases per 100000 people, respectively. The estimates for South-Eastern Asia, including Philippine and Vietnam, were 3.4 and 2.6 cases per 100000 people, respectively. Also, the estimates for Western Asia, including Azerbaijan, Bahrain, Iraq, and Saudi Arabia, were 3.4, 4.7, 4.1, and 3.9 cases per 100000 people, respectively (3). Van den Broek et al. estimated the overall incidence rate of leukemia in the Netherlands for all age groups as 3.8 cases per 100000 and with the ratios of 5.1, and 3.2 cases per 100000 people for males and females, respectively (25).

The rate of incidence of leukemia in Europe was estimated at 3.8 cases per 100000 people for all age groups (26). The rate of incidence was stable in the United States from 1987 to 2001(27). The incidence trend of leukemia was increased in Denmark from 1943 to 2003 (28).

Healey et al. reported the standardized incidence rate of leukemia in Canada as 4.01 cases per 100000 people (29). The rate of incidence of acute leukemia was ranged from 1.93 to 3.51 cases per 100000 people from 2004 to 2007. In addition, 2811 cases of cancer were registered for Iran in 2009 with the rates of 1075 and 1736 cases for females and males, respectively. The standardized incidence rates of leukemia for females and males were estimated at 3.76 and 
Leukaemia

ASR (W) per 100,000, All Ages

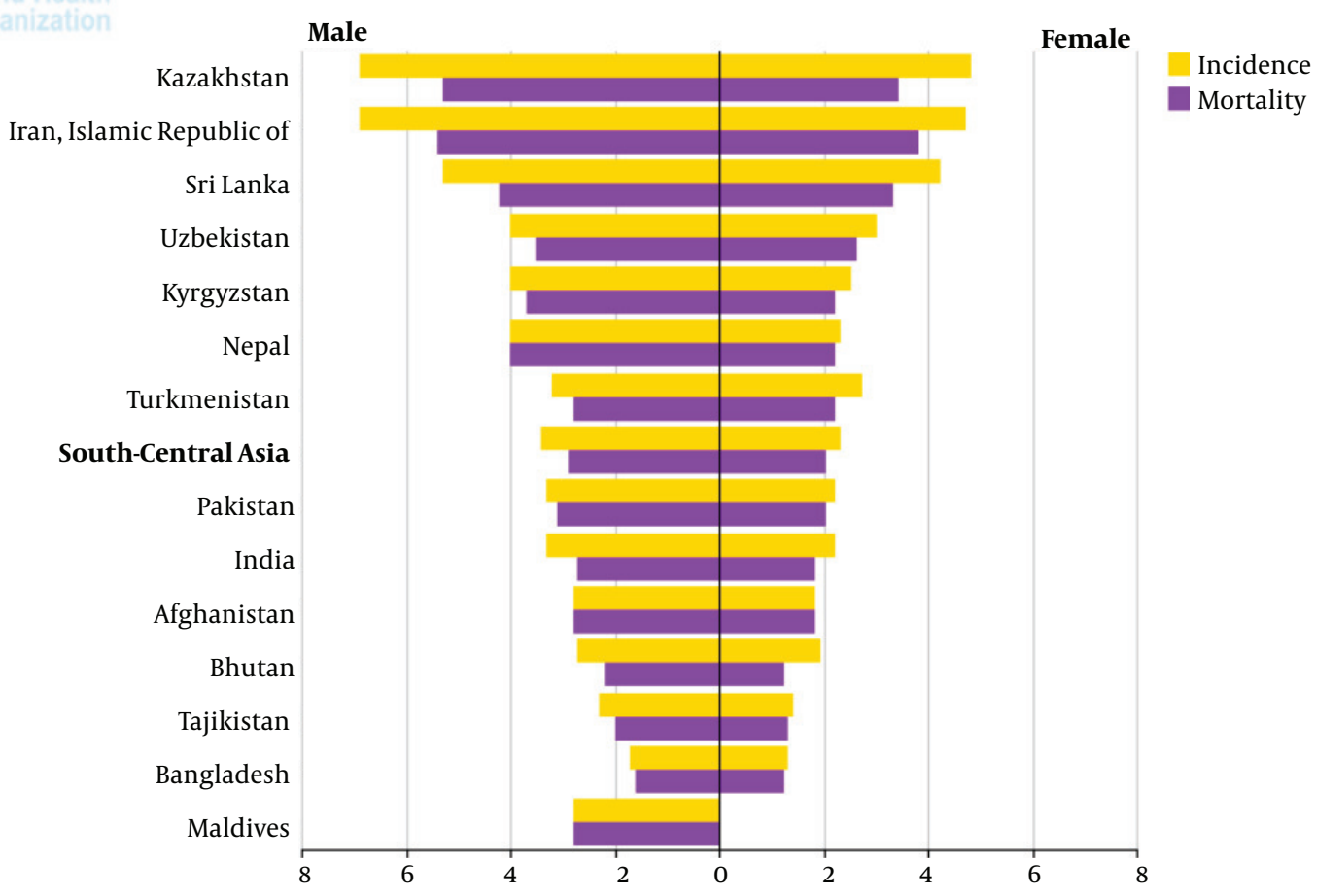

GLOEOCAN 2012 (IARC) (26.1.2018)

Figure 1. Incidence and mortality of leukemia in countries of South-Central Asia in all ages in male and female

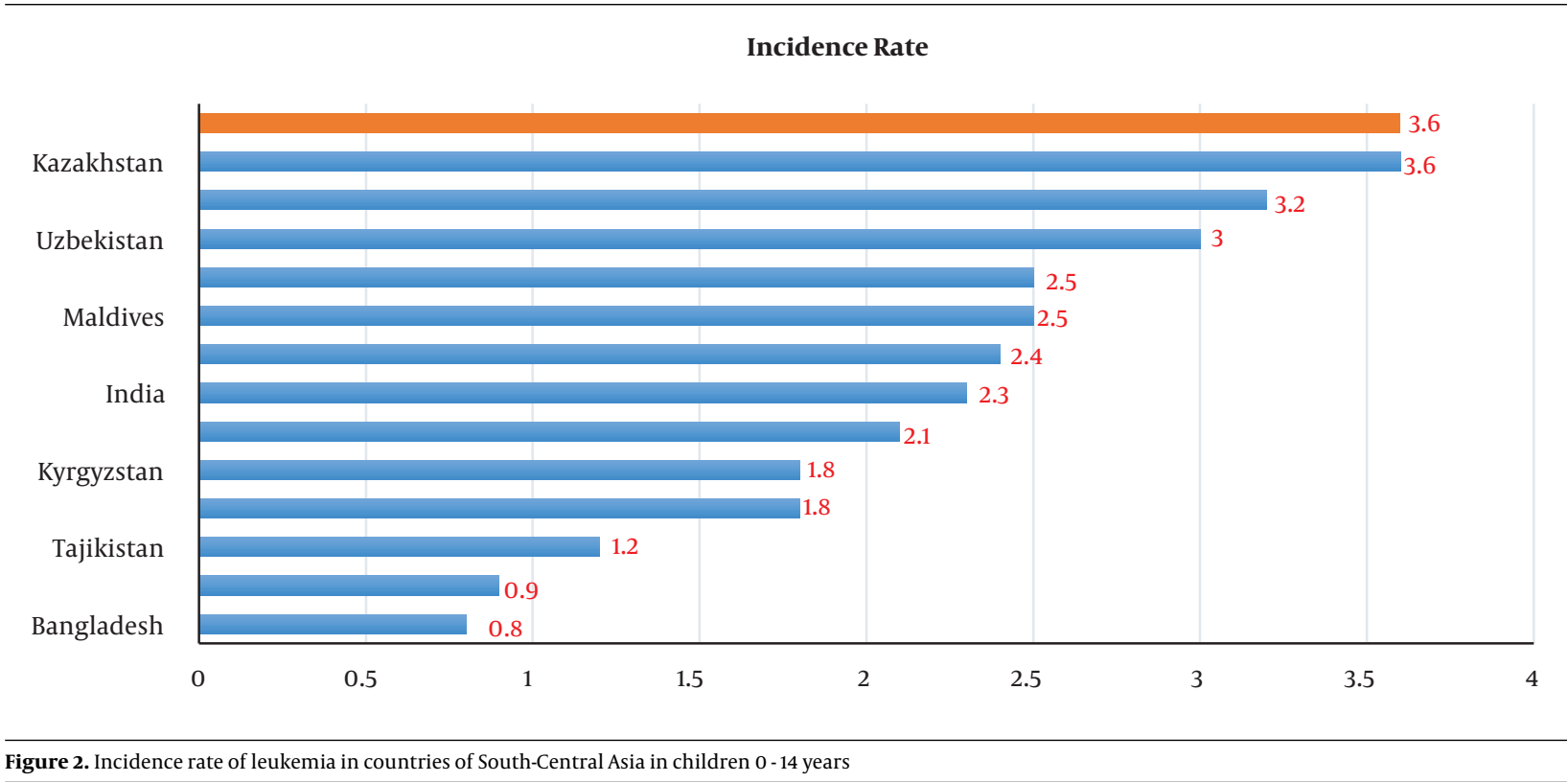




\begin{tabular}{|c|c|c|c|c|c|c|}
\hline \multirow{2}{*}{ Papulation } & \multicolumn{3}{|c|}{ Incidence Rate in 0 - 14 Years } & \multicolumn{3}{|c|}{ Mortality Rate in 0 - 14 Years } \\
\hline & Boy & Girl & Both Sex & Boy & Girl & Both Sex \\
\hline Afghanistan & 2.2 & 1.4 & 1.8 & 2.0 & 1.3 & 1.6 \\
\hline Bangladesh & 1.0 & 0.5 & 0.8 & 0.8 & 0.5 & 0.6 \\
\hline Bhutan & 1.9 & - & 0.9 & 1.9 & - & 0.9 \\
\hline India & 2.8 & 1.8 & 2.3 & 1.7 & 1.1 & 1.4 \\
\hline Iran & 4.3 & 2.9 & 3.6 & 1.7 & 1.8 & 2.1 \\
\hline Kazakhstan & 3.9 & 3.4 & 3.6 & 2.3 & 1.8 & 2.0 \\
\hline Kyrgyzstan & 2.0 & 1.5 & 1.8 & 1.6 & 1.0 & 1.3 \\
\hline Maldives & 4.8 & - & 2.5 & 4.8 & - & 2.5 \\
\hline Nepal & 3.2 & 1.8 & 2.5 & 2.9 & 1.6 & 2.3 \\
\hline Pakistan & 3.2 & 1.5 & 2.4 & 2.6 & 1.2 & 1.8 \\
\hline Sri Lanka & 3.8 & 2.5 & 3.2 & 2.4 & 1.6 & 2.0 \\
\hline Tajikistan & 1.2 & 1.2 & 1.2 & 1.1 & 1.0 & 1.0 \\
\hline Turkmenistan & 2.9 & 2.8 & 2.1 & 2.1 & 1.9 & 2.0 \\
\hline Uzbekistan & 3.7 & 2.2 & 3.0 & 2.8 & 1.7 & 2.2 \\
\hline
\end{tabular}

5.09 cases per 100000 people, respectively $(15,29)$.

In the study of Hjalgrim et al. performed on the specific incidence of leukemia based on age and gender in infants in 5 Scandinavian countries, including Sweden, Denmark, Norway, Finland, and Ice Land, they estimated the incidence rate of acute lymphoblastic leukemia during the five 4-year periods from 3.84 to 4.03 cases per 100000 people with the annual mean of $0.22 \%$ (30).

The incidence rate of acute leukemia in Iran ranged from 1.93 to 3.51 cases per 100000 people from 2003 to 2006. Moreover, 2811 cases with leukemia were registered from Iran in 2008 with the rates of 1075 and 1736 cases for females and males, respectively. The standardized incidence rates of leukemia for females and males were estimated at 3.76 and 5.09 cases per 100000 people, respectively $(15,29)$. The incidence ratio of acute lymphoblastic leukemia in under 15-year-old infants was reported in Fars province with 32.6 cases per 1 million infants with the prevalence of $57.5 \%$ and $42.5 \%$ in males and females, respectively (31).

Leukemia is often accompanied by fatigue, fever, bleeding, chest pain, and splenomegaly. Therefore, leukemia is one of the common causes of child mortality. Identifying effective factors and controlling them and the focus of screening programs on specific subtypes can lead to early detection and effective treatment of the patients (32).

The highest mortality ratios in under 14-year-old infants in South-Central Asia were reported in Maldives, Nepal, and Uzbekistan as 2.5, 2.3, and 2.2 cases per 100000 people, respectively compared with the lowest mortality ratios in Bangladesh, Bhutan, and Tajikistan as 0.6, 0.9, and 1 case per 100000 people, respectively.

The highest mortality ratios from early infancy to 14 years of age in Eastern Asia were reported in China, and Japan with 2.3, and 0.6 cases per 100000 people, respectively. Also, the highest mortality ratios from early infancy to 14 years of age in South-Eastern Asia were reported in Philippine and Vietnam with 2.2, and 2 cases per 100000 people, respectively. In addition, the highest mortality ratios from early infancy to 14 years of age in Western Asia were reported in Azerbaijan, Bahrain, Iraq, and Saudi Arabia with 2.3, 1.1, 2.9, and 2.3 cases per 100000 people, respectively (3).

Lack of adequate space, proper nutrition and para clinical useful facilities for detecting complications of chemotherapy drugs in addition to cultural and health problems as well as family poverty can increase the mortality rate of this disease. Since the prevalence of factors affecting leukemia varies corresponding the time and population, the study of effective factors in different regions can lead to more accurate identification of factors to reduce the incidence and mortality of the disease.

\subsection{Conclusion}

Monitoring cancer incidence trend is considered one of the most important branches of cancer supervision system. Evaluation of cancer incidence rates could pro- 


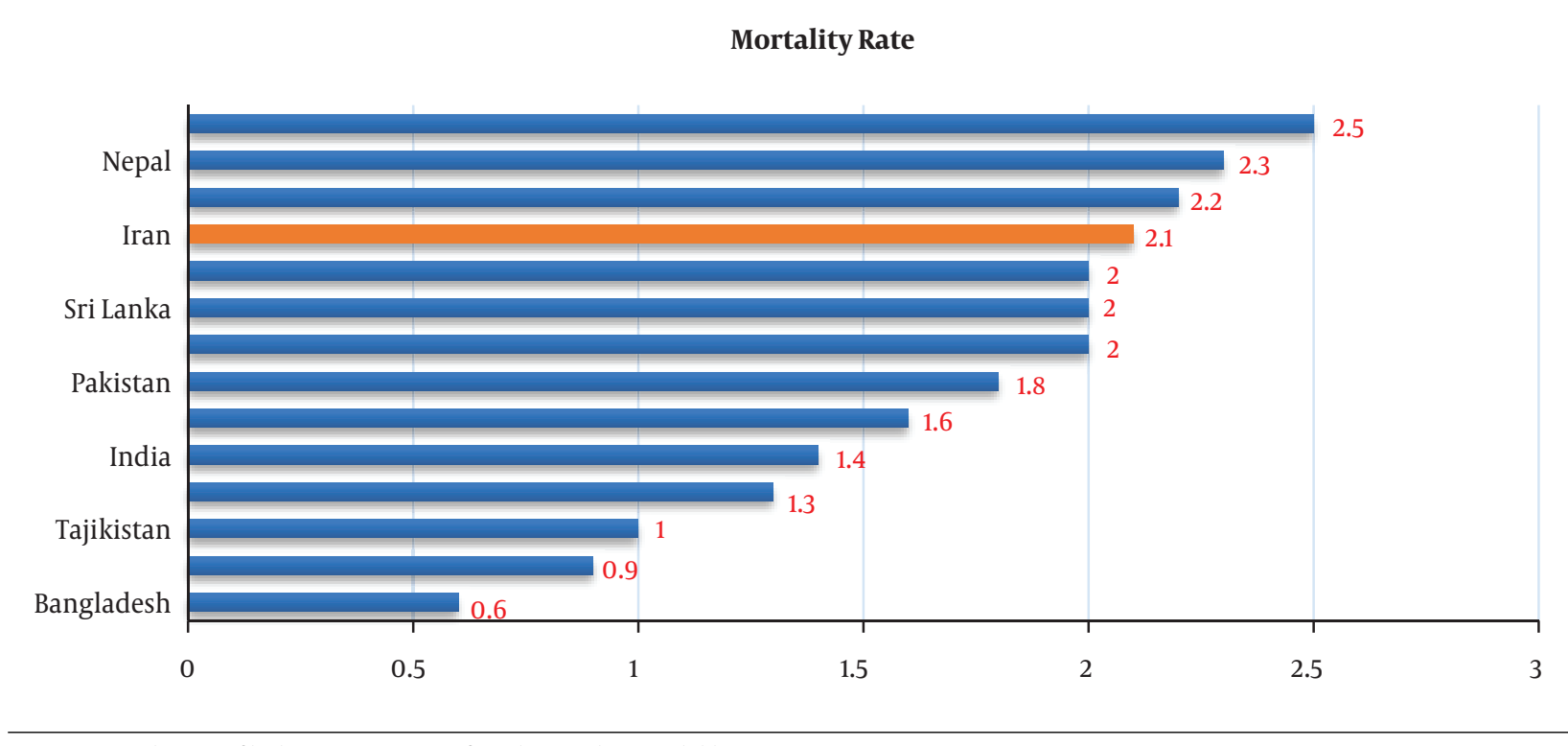

Figure 3. Mortality rate of leukemia in countries of South-Central Asia in children 0 - 14 years

vide important information about risk factors and possible changes that help us to find ways so as to reduce the incidence of cancer in infants. Thus propagating of screening programs, application of correct and on-time diagnosis and treatment of the disease in infants could decline the rate of mortality in these patients.

\section{Footnotes}

Conflict of Interests: The authors declare that they have no conflict of interests.

Ethical Considerations: This research is based on the World Bank's data on cancer.

Funding/Support: None declared.

\section{References}

1. Khazaei S, Rezaeian S, Khazaei Z, Molaeipoor L, Nematollahi S, Lak P, et al. National breast cancer mortality and incidence rates according to the human development index: An ecological study. Adv Breast Cancer Res. 2016;5(1):30-6. doi: 10.4236/abcr.2016.51003.

2. Khazaei S, Mansori K, Soheylizad M, Gholamaliee B, Shadmani FK, Khazaei Z, et al. Epidemiology of lung cancer in Iran: Sex difference and geographical distribution. Middle East J Cancer. 2017;8(4):223-8.

3. Ferlay J, Soerjomataram I, Dikshit R, Eser S, Mathers C, Rebelo M, et al. Cancer incidence and mortality worldwide: Sources, methods and major patterns in GLOBOCAN 2012. Int J Cancer. 2015;136(5):E359-86. doi: 10.1002/ijc.29210. [PubMed: 25220842].

4. Rahimi Pordanjani S, Baeradeh N, Khazaei Z, Goodarzi E, Beiranvand R, Alikhani A, et al. Epidemiological trend and distribution of prevalent cancers in Razavi Khorasan province during 2005-2010, Iran. IntJ Prevent Pub Health Sci. 2017.
5. Davoodi M, Bahadoram S, Bahadoram M, Barahman M, Khazaei Z, Amiri M. Impact of cancers on the kidney function and structure; An ignored entity. J Renal Inj Prevent. 2018;7(3):112-5. doi: 10.15171/jrip.2018.26.

6. Moradi A, Semnani S, Roshandel G, Mirbehbehani N, Keshtkar A, Aarabi M, et al. Incidence of childhood cancers in Golestan province of Iran. Iran JPediatr.2010;20(3):335-42. [PubMed: 23056726]. [PubMed Central: PMC3446043].

7. Bao PP, Zheng Y, Wang CF, Gu K, Jin F, Lu W. Time trends and characteristics of childhood cancer among children age 0-14 in Shanghai. Pediatr Blood Cancer. 2009;53(1):13-6. doi:10.1002/pbc.21939. [PubMed: 19260104].

8. Peris-Bonet R, Salmeron D, Martinez-Beneito MA, Galceran J, MarcosGragera R, Felipe S, et al. Childhood cancer incidence and survival in Spain. Ann Oncol. 2010;21 Suppl 3:iii103-10. doi: 10.1093/annonc/mdq092. [PubMed: 20427353].

9. Norouzirad R, Khazaei Z, Mousavi M, Adineh HA, Hoghooghi M, Khabazkhoob M, et al. Epidemiology of common cancers in Dezful county, southwest of Iran. Immunopathol Persa. 2017;4(1).

10. Pession A, Dama E, Rondelli R, Magnani C, De Rosa M, Locatelli F, et al. Survival of children with cancer in Italy, 1989-98. A report from the hospital based registry of the Italian Association of Paediatric Haematology and Oncology (AIEOP). Eur J Cancer. 2008;44(9):1282-9. doi:10.1016/j.ejca.2008.03.020. [PubMed:18430564].

11. Hayati H, Kebriaeezadeh A, Nikfar S, Akbari Sari A, Troski M, Molla Tigabu B. Treatment costs for pediatrics acute lymphoblastic leukemia; comparing clinical expenditures in developed and developing countries: A review article. Int J Pediatr. 2016;4(12):4033-41.

12. Van Cutsem E, Cunningham D, Maroun J, Cervantes A, Glimelius B. Raltitrexed: Current clinical status and future directions. Ann Oncol. 2002;13(4):513-22. doi:10.1093/annonc/mdf054. [PubMed: 12056700].

13. Hassanzade J, Mohammadi R, Rajaeefard AR. Risk factors in childhood lymphoblastic leukemia in Shiraz-Iran (2009): An epidemilogical study. J Gorgan Univ Med Sci. 2012;14(4):119-24.

14. Ghasemi A, Banihashem A, Ghaemi N, Elmi S, Esmaeili H, Erfani Sayyar R. Evaluation of bone mineral density in children with acute lymphoblastic leukemia (ALL) and non-hodgkin's lymphoma (NHL). Int J Pediatr. 2014;2(2.1):68. 
15. Akramipour R, Pedram M, Zandian KM, Hashemi AAS. [A 5-year-study on children with acute myelocytic leukemia/AML, Ahvaz Shafa Hospital (1996-2001)]. Behbood. 2007;11(2 (33)):180-6. Persian.

16. Desandes E, Berger C, Tron I, Demeocq F, Bellec S, Blouin P, et al. Childhood cancer survival in France, 1990-1999. Eur J Cancer. 2008;44(2):205-15. doi: 10.1016/j.ejca.2007.11.016. [PubMed: 18077152].

17. Eden T. Aetiology of childhood leukaemia. Cancer Treat Rev. 2010;36(4):286-97. doi: 10.1016/j.ctrv.2010.02.004. [PubMed: 20223594]

18. Belson M, Kingsley B, Holmes A. Risk factors for acute leukemia in children: A review. Environ Health Perspect. 2007;115(1):138-45. doi: 10.1289/ehp.9023. [PubMed: 17366834]. [PubMed Central PMC1817663].

19. Spix C, Spallek J, Kaatsch P, Razum O, Zeeb H. Cancer survival among children of Turkish descent in Germany 1980-2005: A registrybased analysis. BMC Cancer. 2008;8:355. doi: 10.1186/1471-2407-8-355 [PubMed:19040749]. [PubMed Central: PMC2628927].

20. Vrooman LM, Silverman LB. Childhood acute lymphoblastic leukemia: Update on prognostic factors. Curr Opin Pediatr. 2009;21(1):1-8. doi: 10.1097/MOP.ob013e32831fif24. [PubMed 19242236].

21. Bajel A, George B, Mathews V, Viswabandya A, Kavitha ML, Srivastava $A$, et al. Treatment of children with acute lymphoblastic leukemia in India using a BFM protocol. Pediatr Blood Cancer. 2008;51(5):621-5. doi: 10.1002/pbc.21671. [PubMed: 18688848].

22. Zareifar S, Almasi-Hashiani A, Karimi M, Tabatabaee S, Ghiasvand R. [Five-year survival rate of pediatric leukemia and its determinants]. Koomesh. 2012;14(2):13-9. Persian.

23. Nikpour S, Rahimian SH, Shokrabi S, Haghani H. [Related factors of acute leukemia in children and the role of breast feeding]. Iran J Endocrinol Metabol. 2012;14(SN 61):63-7. Persian.

24. Ferlay J, Shin H, Bray F, Forman D, Mathers C, Parkin D. Media centre IARC news: Globocan 2008: Cancer incidence and mortality worldwide. Lyon: International Agency for Research on Cancer; 2013. Available from: https://www.iarc.fr/media-centre-iarc-news-29/.
25. van den Broek EC, Kater AP, van de Schans SA, Karim-Kos HE, JanssenHeijnen ML, Peters WG, et al. Chronic lymphocytic leukaemia in the Netherlands: Trends in incidence, treatment and survival, 19892008. Eur J Cancer. 2012;48(6):889-95. doi: 10.1016/j.ejca.2011.06.053. [PubMed: 21795040].

26. Sant M, Allemani C, Tereanu C, De Angelis R, Capocaccia R, Visser O, et al. Incidence of hematologic malignancies in Europe by morphologic subtype: Results of the HAEMACARE project. Blood. 2010;116(19):372434.

27. Dores GM, Anderson WF, Curtis RE, Landgren O, Ostroumova E, Bluhm EC, et al. Chronic lymphocytic leukaemia and small lymphocytic lymphoma: Overview of the descriptive epidemiology. Br J Haematol. 2007;139(5):809-19. doi: 10.1111/j.1365-2141.2007.06856.x. [PubMed: 17941952].

28. Thygesen LC, Nielsen OJ, Johansen C. Trends in adult leukemia incidence and survival in Denmark, 1943-2003. Cancer Causes Control. 2009;20(9):1671-80. doi: 10.1007/s10552-009-9417-9. [PubMed: 19672681].

29. Healey R, Patel JL, de Koning L, Naugler C. Incidence of chronic lymphocytic leukemia and monoclonal B-cell lymphocytosis in Calgary, Alberta, Canada. Leuk Res. 2015;39(4):429-34. doi: 10.1016/j.leukres.2015.01.015. [PubMed: 25703352].

30. Hjalgrim LL, Rostgaard K, Schmiegelow K, Soderhall S, Kolmannskog $S$, Vettenranta K, et al. Age- and sex-specific incidence of childhood leukemia by immunophenotype in the Nordic countries. J Natl Cancer Inst. 2003;95(20):1539-44. doi: 10.1093/jnci/djg064. [PubMed: 14559876].

31. Heshmatyar M, Hajinaghdi M. [Comparison of clinical manifestations, age and sex distribution in childhood acute lymphoblastic leukemia and acute meyloblastic leukemia]. Med J Azad Islamic Univ. 2005;15(3):121-4. Persian.

32. Faranoush MHM, Haji-Hoseini R, Vosough P, Falah-Azad V, Mehrvar A. [Effects of L-asparginase administration on anticoagulant proteins and platelet function in patients with acute lymphoblastic leukemia]. Koomesh. 2010;12(2):175-80. Persian. 
Table 1. Incidence and Mortality of Leukemia in South-Central Asia by Country in All Group Ages

\begin{tabular}{|c|c|c|c|c|c|c|}
\hline & \multicolumn{2}{|c|}{ Incidence } & \multicolumn{2}{|c|}{ Mortality } & \multicolumn{2}{|c|}{ 5-Year Prevalence } \\
\hline & No. (\%) & ASR, W & No. (\%) & ASR, W & No. (\%) & Prop \\
\hline \multicolumn{7}{|l|}{ Afghanistan } \\
\hline Male & $433(4.7)$ & 2.8 & $417(5.2)$ & 2.8 & $358(2.2)$ & 3.8 \\
\hline Female & $253(2.8)$ & 1.8 & $238(3.2)$ & 1.8 & $201(0.8)$ & 2.3 \\
\hline \multicolumn{7}{|l|}{ Bangladesh } \\
\hline Male & $1213(2.0)$ & 1.7 & $1121(2.3)$ & 1.7 & $935(0.9)$ & 1.7 \\
\hline Female & $862(1.4)$ & 1.3 & $810(1.9)$ & 1.2 & $775(0.5)$ & 1.5 \\
\hline Both Sex & $2075(1.7)$ & 1.5 & $1931(2.1)$ & 1.4 & $1710(0.7)$ & 1.6 \\
\hline Male & $10(4.1)$ & 2.7 & $8(3.8)$ & 2.2 & $20(5.1)$ & 6.9 \\
\hline Female & $6(2.8)$ & 1.9 & $4(2.4)$ & 1.2 & $8(1.9)$ & 3.2 \\
\hline Both Sex & $16(3.5)$ & 2.3 & $12(3.2)$ & 1.7 & $28(3.5)$ & 5.2 \\
\hline \multicolumn{7}{|l|}{ India } \\
\hline Male & $19619(4.1)$ & 3.3 & $16068(4.5)$ & 2.7 & $13954(2.1)$ & 3.1 \\
\hline Female & $12913(2.4)$ & 2.3 & $10644(3.3)$ & 1.9 & $10088(0.9)$ & 2.3 \\
\hline Both Sex & $32532(3.2)$ & 2.8 & $26712(3.9)$ & 2.3 & $24042(1.3)$ & 2.7 \\
\hline \multicolumn{7}{|l|}{ Iran } \\
\hline Male & $2338(5.2)$ & 6.9 & $1822(6.1)$ & 5.4 & $2268(2.9)$ & 7.7 \\
\hline Female & $1588(4.0)$ & 4.7 & $1242(5.3)$ & 3.8 & $1620(1.8)$ & 5.6 \\
\hline \multicolumn{7}{|l|}{ Kazakhstan } \\
\hline Male & $497(2.7)$ & 6.9 & $368(2.9)$ & 5.3 & $458(1.5)$ & 8.0 \\
\hline Female & $440(2.0)$ & 4.8 & $323(3.0)$ & 3.4 & $381(0.7)$ & 5.9 \\
\hline Both Sex & $937(2.3)$ & 5.7 & $691(2.9)$ & 4.1 & $839(1.0)$ & 6.9 \\
\hline \multicolumn{7}{|l|}{ Kyrgyzstan } \\
\hline Male & $93(3.5)$ & 4.0 & $83(4.0)$ & 3.7 & $83(2.0)$ & 4.5 \\
\hline Female & $65(2.1)$ & 2.5 & $56(3.0)$ & 2.2 & $61(0.8)$ & 3.1 \\
\hline Both Sex & $158(2.7)$ & 3.2 & $139(3.5)$ & 2.9 & $144(1.3)$ & 3.8 \\
\hline \multicolumn{7}{|l|}{ Maldives } \\
\hline Male & $4(3.5)$ & 2.8 & $4(5.0)$ & 2.8 & $4(2.1)$ & 3.3 \\
\hline Female & $0(0.0)$ & 0.0 & $0(00)$ & 00 & $0(0.0)$ & 0.0 \\
\hline Both Sex & $4(1.8)$ & 1.4 & $4(3.1)$ & 1.4 & $4(0.8)$ & 1.6 \\
\hline \multicolumn{7}{|l|}{ Nepal } \\
\hline Male & $522(6.2)$ & 4.0 & $497(7.2)$ & 4.0 & $410(2.9)$ & 4.2 \\
\hline Female & $319(3.1)$ & 2.3 & $303(4.1)$ & 2.2 & $289(1.2)$ & 2.8 \\
\hline Both Sex & $841(4.5)$ & 3.1 & $800(5.6)$ & 3.0 & $699(1.8)$ & 3.5 \\
\hline
\end{tabular}

Pakistan 


\begin{tabular}{|c|c|c|c|c|c|c|}
\hline Male & $2872(4.5)$ & 3.3 & $2598(5.4)$ & 3.1 & $2450(2.1)$ & 4.1 \\
\hline Female & $1737(2.1)$ & 2.2 & $1582(3.0)$ & 2.0 & $1728(0.8)$ & 3.0 \\
\hline Both Sex & $4609(3.1)$ & 2.8 & $4180(4.1)$ & 2.6 & $4178(1.2)$ & 3.5 \\
\hline \multicolumn{7}{|l|}{ Sri Lanka } \\
\hline Male & $578(5.7)$ & 5.3 & $465(6.9)$ & 4.2 & $592(3.3)$ & 7.6 \\
\hline Female & $496(3.7)$ & 4.2 & $401(5.6)$ & 3.3 & $439(1.3)$ & 5.4 \\
\hline Both Sex & $1074(4.5)$ & 4.7 & $866(6.2)$ & 3.7 & $1031(2.0)$ & 6.5 \\
\hline \multicolumn{7}{|l|}{ Tajikistan } \\
\hline Male & $7.5(2.9)$ & 2.3 & $64(1.3)$ & 2.0 & $64(1.6)$ & 3.0 \\
\hline Female & $46(1.6)$ & 1.4 & $39(2.1)$ & 1.3 & $38(0.6)$ & 1.6 \\
\hline \multicolumn{7}{|l|}{ Turkmenistan } \\
\hline Male & $77(2.6)$ & 3.2 & $64(3.0)$ & 2.8 & $59(1.3)$ & 3.3 \\
\hline Female & $66(2.1)$ & 2.7 & $54(2.9)$ & 2.2 & $62(0.9)$ & 3.3 \\
\hline Both Sex & $143(2.4)$ & 2.9 & $118(3.0)$ & 2.5 & $121(1.1)$ & 3.3 \\
\hline \multicolumn{7}{|l|}{ Uzbekistan } \\
\hline Male & $529(5.4)$ & 4.1 & $449(6.0)$ & 3.5 & $509(3.3)$ & 5.2 \\
\hline Female & $406(3.2)$ & 3.0 & $346(4.7)$ & 2.6 & $370(1.2)$ & 3.6 \\
\hline Both Sex & $535(4.1)$ & 3.5 & $795(5.3)$ & 3.1 & $879(1.9)$ & 4.4 \\
\hline
\end{tabular}

